\title{
Respuesta vacunal frente a SARS-CoV-2 en trabajadores de un hospital
}

\author{
Vaccine response to SARS-CoV-2 \\ in hospital workers
}

\author{
Susana Sabater-Vidal' ${ }^{1}$ (1) 0000-0003-3591-5721 \\ $M^{\text {a }}$ Carmen Bellido-Cambrón ${ }^{2}$ \\ Alberto Arnedo-Pena ${ }^{3}$ (i) 0000-0002-1071-0984 \\ $\mathrm{M}^{\mathrm{a}}$ Isabel Palomares-Gallego ${ }^{\top}$ \\ Rosa María Larrea-González ${ }^{4}$ \\ Mario Carballido-Fernández ${ }^{4}$ ๑ 0000-0002-7640-1316 \\ Rosario Moreno-Muñoz¹ (i) 0000-0002-0185-5612
}

\begin{abstract}
'Servicio de Microbiología, Hospital General Universitario de Castellón, Castellón, España.
Servicio de Prevención de Riesgos Laborales, Hospital General Universitario de Castellón, Castellón, España.

${ }^{3}$ Universidad Pública de Navarra Departamento de Ciencias de la Salud, Pamplona, España.

${ }^{4}$ Servicio de Medicina Preventiva, Hospital General Universitario de Castellón, Castellón, España.
\end{abstract}

Fechas · Dates

Recibido: 2020.06.10

Aceptado: 2020.08 .25

Publicado: 2021.10.15
Correspondencia · Corresponding Author

Susana Sabater Vidal

tatana9@msn.com 


\section{Resumen}

Introducción: Evaluar la inmunidad de los trabajadores de un hospital tras haber completado la vacunación Pfizer-BionTech, y su relación con factores individuales. También describir los efectos adversos de la vacuna.

Método: Estudio transversal de una muestra de los trabajadores del Hospital General Universitario de Castellón vacunados con dos dosis en enero y febrero de 2021. Un mes después se detectaron: anticuerpos IgG frente a la proteína N (IgG-NP), de IgM frente a la proteína S (IgM-S) y detección cuantitativa de IgG frente a la proteína S (IgG-Quant). Se utilizó un cuestionario para recoger datos demográficos, factores de riesgo y efectos secundarios. En el análisis estadístico se utilizaron modelos de regresión múltiple.

Resultados: La participación fue del 96,8\% (275/284). Presentaron IgG-Quant el 99,6\%, 14,9\% IgM-S, y 4,4\% IgG-NP. El nivel ajustado de IgG-Quant aumentó significativamente con la obesidad, en no fumadores y con positividad IgM-S y/o IgG-NP. La prevalencia de IgM-S era mayor en varones, y se asociaba con los mismos factores que la IgG-Quant. De los infectados por COVID-19, el 42,9\% no presentaron IgG-NP. Un 86,5\% sufrió algún efecto secundario que se asoció a tener IgG-NP, mayores niveles de IgG-Quant, y fue más frecuente en jóvenes y mujeres.

Conclusiones: Todos los participantes desarrollaron inmunidad humoral excepto uno. Tuvieron mayores niveles de anticuerpos los que habían padecido la COVID-19. Un porcentaje alto desarrolló efectos secundarios leves, más frecuentes en los que habían padecido la enfermedad.

Palabras clave: SARS-CoV-2; COVID-19; vacuna Pfizer-BionTech; IgG-Quant, IgM-S; IgG-NP; índice de masa corporal; obesidad; no fumadores; efectos secundarios.

\section{Abstract}

Introduction: The aim of this study was to measure anti-SARS-CoV-2 immunity of hospital workers after a completed 2-dose Pfizer-BionTech vaccination, and to examine factors potentially associated with immunity status. Side effects of the vaccine were also studied.

Method: This was a cross-sectional study of a representative sample of General University Hospital of Castellon workers, vaccinated with two doses in January and February 2021. We measured IgG antibodies against protein N (IgG-NP), IgM against protein S (IgM-S), and quantitative levles of IgG against protein S (IgG-Quant) one month after the last dose. We obtained information on demographic, risk factors, and vaccine side effects via a self-completed questionnaire. For the statistical analysis we used multiple regression models.

Results: Two hundred seventy-five workers participated $(96.8 \%, 275 / 284)$. Positive IgGQuant, IgM-S, and IgG-NP were 99.6\%, 14.9\% and 4.4\%, respectively. Adjusted IgG-Quant levels increased significantly with obesity, nonsmoking status, positive IgM-S, and/or IgGNP. The prevalence of IgM-S was higher in males, and associated with the same factors as those for IgG-Quant. Among those with a history of COVD-19 infection, 42.9\% did not have IgG-NP. Overall $86.5 \%$ of participants had side effects, which were associated with positive IgG-NP, high IgG-Quant levels, younger age, and being female. 
Conclusions: All but one participant developed immunity. Those who had suffered from COVID-19 infection had higher antibody levels. A high proportion of participants had mild secondary effects, especially those with previous COVID-19 infection.

Keywords: SARS-CoV-2, COVID-19, Pfizer-BionTech vaccine, IgG-Quant, IgM-S, IgG-NP, body mass index, obesity, no-smokers, adverse effects.

\section{Introducción}

El virus SARS-CoV-2 causante de la enfermedad denominada COVID-19, es un nuevo coronavirus detectado en China a finales de diciembre de 2019, donde causó un brote de neumonía de etiología desconocida ${ }^{(1)}$. Este virus ha afectado y modificado el modo de vivir de millones de personas ya que es pandémico ${ }^{(2)}$. Ningún país estaba preparado para atender a todos los pacientes que requerían atención médica, ni podían hacer frente a la gravedad que éstos presentaban. En la primera ola no había infraestructuras, ni equipamientos adecuados y tampoco personal suficiente para soportar la gran demanda asistencial(3). Todo se vio agravado por las bajas que se produjeron en el personal(4), ya sea por estar en aislamiento o en cuarentena por la COVID-19, por ser trabajadores vulnerables, con patología de salud mental entre otros. Esta situación ha ido mejorando con el transcurso del tiempo gracias a las medidas preventivas aplicadas y a la posibilidad de vacunación temprana del personal sanitario.

Tras una época de incertidumbre en la que se han probado diversos tratamientos en un intento de curar la enfermedad, la disponibilidad de vacunas frente al SARSCoV-2 ha supuesto un gran avance en el control de la infección ${ }^{(5)}$. Favorecido porque ya se disponía de una amplia y probada experiencia sobre cómo desarrollar vacunas con garantías de calidad, seguridad y eficacia, y de conocimientos previos basados en la experiencia, del tratamiento del SARS y el MERS-CoV(6).

La vacuna de Pfizer-BionTech (BNT162b2) fue la primera aprobada por la Agencia Europea del medicamento (AEM) el 21 de diciembre de 2020(7). A fecha de hoy otras tres vacunas han sido aprobadas: las de Moderna, Astra Zeneca y Janssen. Todas ellas han mostrado niveles adecuados de eficacia y seguridad, si bien presentan diferentes características en cuanto a su logística, eficacia y perfiles de población en las que han sido ensayadas ${ }^{(8)}$. En nuestro centro al inicio de la campaña, se empleó la vacuna de Pfizer-BioNTech(9).

Desde el principio de la pandemia también se han ido desarrollando e incorporado diversas técnicas para el diagnóstico serológico del SARS-CoV-2 (ELISA, CLIA, CMIA) cada vez más sensibles y específicas, que son las características que se requiere de una prueba para poder incorporarla al diagnóstico. Estas pruebas están diseñadas para detectar anticuerpos frente a diferentes epítopos del virus, S: Spike (espícula) y N: Nucleocápside. La vacuna genera anticuerpos IgG contra la espícula (S) y algunas pruebas serológicas permiten detectarlos y cuantificarlos ${ }^{(10)}$. La infección natural genera una respuesta de anticuerpos tanto frente al epítopo de la nucleocápside como a de la espícula. 
El objetivo de nuestro trabajo fue determinar la respuesta de anticuerpos anti SARS-CoV-2, mediante una técnica cuantitativa, en trabajadores sanitarios y no sanitarios tras haber completado la vacunación con Pfizer-BionTech, estimar las variables asociadas a la efectividad de esta vacuna, así como describir los efectos secundarios que produce.

\section{Métodos}

Se estudió una muestra representativa y aleatoria de los trabajadores, tanto sanitarios como no sanitarios del Hospital General Universitario de Castellón, que entre el 8 de enero y el 12 de febrero de 2021 completaron la vacunación. Se excluyeron los trabajadores no vacunados y los que no habían completado la pauta de vacunación un mes antes del inicio del estudio. Pasado un mes realizamos un estudio transversal para conocer el estado inmunitario producido por la vacuna de Pfizer-BioNTech y los efectos secundarios que esta había producido.

Los datos de los profesionales vacunados fueron registrados por el Servicio de Medicina Preventiva en una aplicación diseñada por los informáticos del hospital. En ella se introducían datos demográficos, el número SIP (Sistema de Información Poblacional), y fecha en que se administraron las vacunas. A cada vacunado la aplicación le asignaba un número de identificación anonimizado automáticamente.

\section{Tamaño de la muestra estudiada}

Se realizó un muestreo aleatorio simple del total del personal que había completado la vacunación $(n=2800)$ hasta el 12 de febrero. Para calcular el tamaño de la muestra se utilizó el programa Epi-Info versión $7^{(11)}$. Considerando la eficacia de la vacuna Pfizer-BionTech que se ha estimado es de un $95 \%(12,13)$, y considerando que hasta un $10-11 \%$ de los profesionales sanitarios podían haber sufrido la infección frente SARS-CoV-19(14,15) y que otro 10\% podían ser posibles pérdidas, el tamaño muestral resultante fue de 284 trabajadores. Con esta muestra se detectaría una tasa de respuesta de la vacunación del $80 \%$ con un intervalo de confianza del $95 \%$ y una precisión del $5 \%$. Partiendo del censo de trabajadores vacunados, y mediante el programa Open-Epi(16) se obtuvo una lista de números aleatorios para configurar la muestra de participantes ( $n=284)$.

Se contactó telefónicamente con las personas de la muestra y se les preguntó si aceptaban participar en el estudio. Se repitió un segundo muestreo para reemplazar los participantes que no habían aceptado la primera invitación. La muestra final fue de 275 trabajadores.

\section{Cuestionario post-vacunación}

A los trabajadores que dieron su conformidad, se les citó para la extracción de una muestra de sangre. Previamente los participantes auto-cumplimentaron un consentimiento informado, la autorización para que sus muestras se pudiesen al- 
macenar en el biobanco del hospital y un cuestionario post-vacunación (anexo 1). En él se recogían variables demográficas, peso, altura, ocupación, estilos de vida, exposición y/o enfermedad por COVID-19, situación de salud, patologías previas, fecha de la vacunación frente al COVID-19 y potenciales efectos secundarios.

\section{Técnicas de determinación de anticuerpos anti-SARS-CoV-2}

Todas las determinaciones de anticuerpos se realizaron con el analizador automatizado Alinity de Abbott( ${ }^{(10)}$, que utiliza la tecnología de inmunoanálisis quimioluminiscente de micropartículas (CMIA). Los ensayos utilizados fueron: detección cualitativa de anticuerpos IgG (Abbott SARS-CoV-2 IgG assay) frente a la proteína N(IgG-NP), detección semicuantitativa de IgM (Abbott SARS-CoV-2 IgM assay) frente a la proteína S (IgM-S) y detección cuantitativa de IgG (Abbott SARS- CoV-2 IgGII assay) frente a la proteína S (IgG-Quant).

\section{Análisis estadístico de los datos}

Se realizó un análisis descriptivo de las características de los participantes, y se estimaron las proporciones de respuesta de la vacunación y los efectos adversos con un intervalo de confianza (IC) del 95\% mediante una distribución binomial. Se emplearon pruebas estadísticas como Chi2, prueba exacta de Ficher para comparar variables cualitativas y las pruebas de Mann-Whitney y de Kruscal-Wallis para comparar variables cuantitativas. Se emplearon la regresión lineal simple, la regresión múltiple para analizar los niveles de IgG-Quant como variable cuantitativa y la regresión de Poisson robusta para la respuesta a IgG-NP e IgM-S y para analizar los efectos secundarios de la vacunación. Se comprobó la bondad de ajuste de los modelos de regresión. A modo exploratorio, se utilizó el análisis de la varianza para desarrollar un modelo predictivo de los niveles de IgG-Quant en función de las variables estudiadas, incluyendo la edad por grupos, sexo, índice de masa corporal $\left(\mathrm{Kg} / \mathrm{m}^{2}\right)$ y el hábito tabáquico. Se utilizó el método Directed Acyclic Graphs (DAGs) (17) para obtener las variables de ajuste incluidas en los modelos multivariantes. Todos los análisis estadísticos se realizaron con el programa STATA@ versión 14.

\section{Aprobación por el Comité de Ética}

Para la realización del estudio se obtuvo la aprobación del Comité Ético de Investigación con medicamentos (CEIm) del Hospital General Universitario de Castellón.

\section{Resultados}

La participación fue del 96,8\% (275/284), 205 eran mujeres (75,6\%) y 70 varones $(25,4 \%)$ con una edad media de 44,6+/- 11,1 años (rango 20-69). La ocupación más frecuente $(34,3 \%)$ fue enfermería. Los estilos de vida sugieren una menor prevalencia de obesidad y tabaquismo en las ocupaciones sanitarias, siendo similar en cuanto a consumo de alcohol y ejercicio físico en todas. Respecto a la prevalencia de enfermedad, fue más elevada en 
personal de mantenimiento y administración, siendo las endocrino-metabólicas las más frecuentes. La exposición a la COVID-19 fue del 66,8\% e indicaron que habían pasado la enfermedad el 8,5\%. En la tabla 1 se recogen las características de la población.

Tabla 1. Características generales de la muestra de estudio.

\begin{tabular}{|c|c|c|c|c|c|c|c|}
\hline Variables & Categorías & $\begin{array}{c}\text { Medici- } \\
\text { na } n=63 \\
N(\%)\end{array}$ & $\begin{array}{l}\text { Enfer- } \\
\text { mería } \\
\mathrm{n}=93 \\
\mathrm{~N}(\%)\end{array}$ & $\begin{array}{c}\text { Auxiliar } \\
n=45 \\
N(\%)\end{array}$ & $\begin{array}{c}\text { Ce- } \\
\text { lador } \\
n=18 \\
N(\%)\end{array}$ & $\begin{array}{l}\text { Otras } \\
\mathrm{n}=52 \\
\mathrm{~N}(\%)\end{array}$ & $\begin{array}{l}\text { Totales } \\
\mathrm{n}=271^{\mathrm{a}}\end{array}$ \\
\hline \multirow{2}{*}{ Sexo } & Varones & $27(42,8)$ & $13(14)$ & $2(4,4)$ & $7(38,9)$ & $18(34,6)$ & $\begin{array}{c}205 \\
(75,6) \\
\end{array}$ \\
\hline & Mujeres & $36(57,1)$ & $80(86)$ & $\begin{array}{c}43 \\
(95,6) \\
\end{array}$ & $\begin{array}{c}11 \\
(61,1) \\
\end{array}$ & $34(65,4)$ & $70(25,8)$ \\
\hline \multirow{6}{*}{ Edad (años) } & $<25$ & $1(1,6)$ & $4(4,3)$ & $0(0)$ & $0(0)$ & $1(1,9)$ & $6(2,2)$ \\
\hline & $35-34$ & $21(33)$ & $14(15,1)$ & $8(17,8)$ & $1(5,6)$ & $3(5,8)$ & $47(17,3)$ \\
\hline & $35-44$ & $20(31,7)$ & $31(33,3)$ & $\begin{array}{c}11 \\
(24,4) \\
\end{array}$ & $4(22,2)$ & $15(28,8)$ & $81(29,9)$ \\
\hline & $45-54$ & $9(14,3)$ & $24(25,8)$ & $\begin{array}{c}13 \\
(28,9) \\
\end{array}$ & $7(38,9)$ & $16(30,8)$ & $69(25,5)$ \\
\hline & $55-64$ & $8(12,7)$ & $20(21,5)$ & $\begin{array}{c}12 \\
(26,7) \\
\end{array}$ & $6(33,3)$ & $13(25,0)$ & $59(21,8)$ \\
\hline & $\begin{array}{c}64 \text { y más } \\
\text { años }\end{array}$ & $4(6,3)$ & $0(0)$ & $1(2.2)$ & $0(0)$ & $4(7,7)$ & $9(3,3)$ \\
\hline \multirow{3}{*}{$\begin{array}{l}\text { Consumo de } \\
\text { alcohol }^{\circ}\end{array}$} & Nunca & $24(38,1)$ & $38(40,9)$ & $\begin{array}{c}20 \\
(44,4) \\
\end{array}$ & $\begin{array}{c}10 \\
(55,6) \\
\end{array}$ & $22(42,3)$ & $\begin{array}{c}114 \\
(42,1) \\
\end{array}$ \\
\hline & Esporádico & $37(58,7)$ & $52(55,9)$ & $\begin{array}{c}24 \\
(53,3) \\
\end{array}$ & $8(44,4)$ & $28(53,8)$ & $149(55)$ \\
\hline & Habitual & $2(3,2)$ & $3(3,2)$ & $0(0)$ & $0(0)$ & $1(1.9)$ & $6(2,2)$ \\
\hline \multirow{2}{*}{ Ejercicio físico } & Si & $38(60,3)$ & $61(65,6)$ & $\begin{array}{c}26 \\
(57,8) \\
\end{array}$ & $\begin{array}{c}12 \\
(66,7) \\
\end{array}$ & $28(53,8)$ & $\begin{array}{c}165 \\
(60,9) \\
\end{array}$ \\
\hline & No & $25(39,7)$ & $32(34,4)$ & $\begin{array}{c}19 \\
(42,2)\end{array}$ & $6(33,3)$ & $24(46,2)$ & $\begin{array}{c}104 \\
(38,4)\end{array}$ \\
\hline \multirow{3}{*}{$\begin{array}{l}\text { Consumo } \\
\text { tabacod }\end{array}$} & No fumador & $48(76,2)$ & $54(58,1)$ & $\begin{array}{c}19 \\
(42,2) \\
\end{array}$ & $6(33,3)$ & $25(48,1)$ & $\begin{array}{c}152 \\
(56,1) \\
\end{array}$ \\
\hline & Ex fumador & $6(9,5)$ & $17(18,3)$ & $\begin{array}{c}13 \\
(28,9) \\
\end{array}$ & $5(27,8)$ & $14(26,9)$ & $55(20,3)$ \\
\hline & Fumador & $9(14,3)$ & $20(21,5)$ & $\begin{array}{c}11 \\
(24,4) \\
\end{array}$ & $7(38,9)$ & $12(23,1)$ & $59(21,8)$ \\
\hline \multirow{4}{*}{$\begin{array}{l}\text { Índice masa cor- } \\
\text { porale }\left(\mathrm{kg} / \mathrm{m}^{2}\right)\end{array}$} & $<18.5$ & $1(1,6)$ & $2(2,2)$ & $1(2,2)$ & $0(0)$ & $1(1,9)$ & $5(1,8)$ \\
\hline & 18.5-24.9 & $42(66,7)$ & $58(62,4)$ & $\begin{array}{c}23 \\
(51,1)\end{array}$ & $7(38,9)$ & $23(44,2)$ & $\begin{array}{c}153 \\
(56,5)\end{array}$ \\
\hline & $25.0-29.9$ & $15(23,8)$ & $24(25,8)$ & $\begin{array}{c}1 \\
2(26,7) \\
\end{array}$ & $4(22,2)$ & $17(32,7)$ & $72(26,6)$ \\
\hline & $\geq 30.0$ & $4(6,3)$ & $9(9,7)$ & $7(15,6)$ & $\begin{array}{c}5(27, \\
8)\end{array}$ & $7(13,5)$ & $32(11,8)$ \\
\hline
\end{tabular}




\begin{tabular}{|c|c|c|c|c|c|c|c|}
\hline Variables & Categorías & $\begin{array}{c}\text { Medici- } \\
\text { na } n=63 \\
N(\%)\end{array}$ & $\begin{array}{l}\text { Enfer- } \\
\text { mería } \\
\mathrm{n}=93 \\
\mathrm{~N}(\%)\end{array}$ & $\begin{array}{c}\text { Auxiliar } \\
\mathrm{n}=45 \\
\mathrm{~N}(\%)\end{array}$ & $\begin{array}{l}\text { Ce- } \\
\text { lador } \\
\mathrm{n}=18 \\
\mathrm{~N}(\%)\end{array}$ & $\begin{array}{l}\text { Otras } \\
n=52 \\
N(\%)\end{array}$ & $\begin{array}{l}\text { Totales } \\
\mathrm{n}=271^{\text {a }}\end{array}$ \\
\hline \multirow{2}{*}{$\begin{array}{l}\text { Padecer alguna } \\
\text { enfermedad }\end{array}$} & $\mathrm{Si}$ & $10(15.9)$ & $36(38,7)$ & $18(40)$ & $5(27,8)$ & $21(40,4)$ & $90(33,2)$ \\
\hline & No & $53(84,1)$ & $57(61,3)$ & $27(60)$ & $\begin{array}{c}13 \\
(72,2)\end{array}$ & $31(59,6)$ & $\begin{array}{c}18 \\
1(66,8)\end{array}$ \\
\hline \multirow{2}{*}{$\begin{array}{l}\text { Enf. Endocri- } \\
\text { no-metabólica }\end{array}$} & $\mathrm{Si}$ & $3(4,8)$ & $15(16,1)$ & $6(13,3)$ & $3(16,7)$ & $12(23,1)$ & $39(14,3)$ \\
\hline & No & $60(95,2)$ & $78(83,9)$ & $\begin{array}{c}39 \\
(86.7)\end{array}$ & $\begin{array}{c}15 \\
(83,3)\end{array}$ & $40(76,9)$ & $\begin{array}{c}232 \\
(85,7)\end{array}$ \\
\hline \multirow{2}{*}{$\begin{array}{l}\text { Toma algún } \\
\text { medicamento }\end{array}$} & $\mathrm{Si}$ & $11(17,5)$ & $31(33,3)$ & $\begin{array}{c}17 \\
(37,8)\end{array}$ & $5(27,8)$ & $21(40,4)$ & $85(31,3)$ \\
\hline & No & $52(82,5)$ & $62(66,7)$ & $\begin{array}{c}28 \\
(62,2)\end{array}$ & $\begin{array}{c}13 \\
(72,2)\end{array}$ & $31(59,6)$ & $\begin{array}{c}186 \\
(68,6)\end{array}$ \\
\hline \multirow[b]{2}{*}{ Toma vitaminas } & $\mathrm{Si}$ & $10(15,9)$ & $17(18,3)$ & $7(15,6)$ & $4(22,2)$ & $4(7,7)$ & $42(15,5)$ \\
\hline & No & $53(84,1)$ & $76(81,7)$ & $\begin{array}{c}38 \\
(84,4)\end{array}$ & $\begin{array}{c}14 \\
(77,8)\end{array}$ & $48(92,3)$ & $\begin{array}{c}229 \\
(84,5)\end{array}$ \\
\hline \multirow[b]{2}{*}{ Toma vitamina D } & $\mathrm{Si}$ & $5(7,9)$ & $7(7,5)$ & $2(4,4)$ & $0(0)$ & $3(5,8)$ & $17(6,3)$ \\
\hline & No & $58(92,1)$ & $86(92,5)$ & $\begin{array}{c}43 \\
(95,6)\end{array}$ & $\begin{array}{c}18 \\
(100)\end{array}$ & $49(94,2)$ & $\begin{array}{c}254 \\
(93,7)\end{array}$ \\
\hline \multirow{4}{*}{ Estado de Saludf } & Mala & $0(0)$ & $0(0)$ & $0(0)$ & $0(0)$ & $0(0)$ & $0(0)$ \\
\hline & Regular & $1(1,6)$ & $6(6.5)$ & $5(0,11)$ & $1(5,6)$ & $5(9,6)$ & $18(3)$ \\
\hline & Buena & $16(25,4)$ & $50(53,8)$ & $\begin{array}{c}29 \\
(64,4)\end{array}$ & $\begin{array}{c}12 \\
(66,7)\end{array}$ & $33(63,5)$ & $\begin{array}{c}140 \\
(51,7)\end{array}$ \\
\hline & Muy buena & $45(71,4)$ & $37(39,8)$ & $\begin{array}{c}11 \\
(24,4) \\
\end{array}$ & $5(27,8)$ & $14(26,9)$ & $\begin{array}{c}112 \\
(41,3) \\
\end{array}$ \\
\hline \multirow{2}{*}{$\begin{array}{l}\text { Exposición } \\
\text { COVID-19 }\end{array}$} & $\mathrm{Si}$ & $47(74,6)$ & $71(76,3)$ & $\begin{array}{c}29 \\
(64,4)\end{array}$ & $\begin{array}{c}14 \\
(77,8)\end{array}$ & $20(38,5)$ & $\begin{array}{c}181 \\
(66,8)\end{array}$ \\
\hline & No & $16(25,4)$ & $22(23,6)$ & $\begin{array}{c}16 \\
(35,6) \\
\end{array}$ & $4(22,2)$ & $32(61,5)$ & $90(33,2)$ \\
\hline \multirow[b]{2}{*}{ Enf. COVID-199 } & $\mathrm{Si}$ & $5(7,9)$ & $8(8,6)$ & $4(8,9)$ & $2(11,1)$ & $4(7,7)$ & $23(8,5)$ \\
\hline & No & $58(92,1)$ & $85(91,4)$ & $\begin{array}{c}40 \\
(88,9)\end{array}$ & $\begin{array}{c}16 \\
(88,9)\end{array}$ & $47(90,4)$ & $\begin{array}{c}248 \\
(91,5)\end{array}$ \\
\hline \multirow{2}{*}{$\begin{array}{l}\text { CovID-19 confir- } \\
\text { madoh }\end{array}$} & Si & $4(6,3)$ & $7(7,5)$ & $3(6,7)$ & $2(11,1)$ & $5(9,6)$ & $21(7,6)$ \\
\hline & No & $59(93,7)$ & $86(92,5)$ & $\begin{array}{c}42 \\
(93,3)\end{array}$ & $\begin{array}{c}16 \\
(88,9)\end{array}$ & $47(90,4)$ & $(2,4)$ \\
\hline
\end{tabular}

(a)4 participantes sin información de la ocupación. (b) 4 participantes sin información. (c) 1 participante sin información. (d) 5 participantes sin información. (e) 8 participantes sin información. (f) 1 participante sin información. (g) 2 participantes sin información. (h) Confirmación por el laboratorio SARS-COV-2 PCR y/o anti-lgG-NP.

En la tabla 2 se muestra la distribución de los trabajadores según la prevalencia de anticuerpos frente al SARS-CoV-2 (UA/ml) y su relación con las variables estudiadas. El 99.6\% (95\% IC 97,0-99,9) de los participantes presentaron anticuerpos IgG-Quant (274/275), 14,9\% (41/275) (95\% IC 10,9-19,7) anticuerpos IgM-S, y 4,4\% anticuerpos IgG-NP (12/275) (95\% IC 2,3-7,5). Solo una trabajadora no desarrolló inmunidad humoral, posiblemente porque estaba bajo tratamiento inmunosupresor. La media geométrica de los niveles de anticuerpos IgG-Quant era 9.130,7 UA/ $\mathrm{ml}(95 \%$ IC 8.175,8-10.197,0). Estos aumentaban significativamente en los jóve- 
nes, los no fumadores, al presentar obesidad (IMC>30.0 kg/m²), sufrir efectos por la segunda dosis de vacuna e historia de infección por COVID-19; destacando que los participantes IgG-NP positivos tenían de media niveles de IgG-Quant 1.96 veces mayor que los negativos (17.366,9 $\mathrm{UA} / \mathrm{ml}$ versus $8.866,7 \mathrm{UA} / \mathrm{ml})$. El tiempo medio transcurrido entre la segunda dosis y el análisis de anticuerpos fue de 34,2 $\pm 6,1$ días, y no afectó a los títulos de anticuerpos.

De los 23 participantes con historia de COVID-19, 15 tenían PCR positiva y 8 PCR negativas; 10 tenían anticuerpos IgG-NP positivos y 13 fueron negativos. Dos participantes IgG-NP positivos desconocían que hubiesen pasado la enfermedad. De los 21 que tenían confirmación por laboratorio de COVID-19, en 9 no se detectaron $\operatorname{lgG}-\mathrm{NP}(42,9 \%)$.

Tabla 2. Media de niveles de IgG-Quant y prevalencia de anticuerpos IgG-Quant, IgM-S, IgG-NP en función de las variables estudiadas.

\begin{tabular}{|c|c|c|c|c|c|c|c|}
\hline Variables & $\begin{array}{l}\text { Cate- } \\
\text { gorías }\end{array}$ & IgG-Quant & $\mathrm{p}$-valor & $\operatorname{lgM}-S$ & $\mathrm{p}$-valor & $\begin{array}{l}\text { IgG-NP } \\
\mathrm{n}(\%)\end{array}$ & $\mathrm{p}$-valor \\
\hline \multicolumn{2}{|c|}{$\begin{array}{l}\text { Número de personas } \\
\text { con anticuerpos } n(P)\end{array}$} & $274(99,6)$ & - & $41(14,9)$ & - & $12(4,4)$ & - \\
\hline \multirow{2}{*}{ Sexo } & Varones & $12970,3 \pm 9309,3$ & 0,472 & $17(41,5)$ & 0,11 & $4(33,3)$ & 1,000 \\
\hline & Mujeres & $11978,4 \pm 8926,6$ & & $24(58,5)$ & & $8(66,7)$ & \\
\hline \multirow{6}{*}{ Edad (años) } & $<25$ & $15539,5 \pm 7639,5$ & 0,130 & $2(4,9)$ & 0,983 & 0 & 1,000 \\
\hline & 25-34 & $14871,4 \pm 9246,5$ & 0,009 & $6(14,6)$ & & $3(25)$ & \\
\hline & $35-44$ & $10042,6 \pm 7612,9$ & 0,007 & $14(34,1)$ & & $3(25)$ & \\
\hline & $45-54$ & $\begin{array}{c}12140,5 \pm \\
10081,0\end{array}$ & 0,367 & $9(22)$ & & $4(33,3)$ & \\
\hline & $55-64$ & $13691,3 \pm 9224,8$ & 0,063 & $9(22)$ & & $2(16,7)$ & \\
\hline & 65 y más & $6544,3 \pm 2386,8$ & 0,043 & $1(2,4)$ & & 0 & \\
\hline \multirow{2}{*}{ Consumo alcohol . } & Si & $12519,1 \pm 8607,0$ & 0,220 & $25(61)$ & 1,000 & $5(41,7)$ & 0,684 \\
\hline & No & $11844,6 \pm 9540,8$ & & $16(39)$ & & $7(58,3)$ & \\
\hline \multirow[t]{2}{*}{ Ejercicio físico } & Si & $11831,0 \pm 8598,2$ & 0.459 & $27(65.9)$ & 1,000 & $\begin{array}{c}10 \\
(83,3) \\
\end{array}$ & 0,371 \\
\hline & No & $12839,8 \pm 9632,7$ & & $14(34.1)$ & & $2(16,7)$ & \\
\hline \multirow{3}{*}{ Consumo tabaco } & $\begin{array}{l}\text { No fu- } \\
\text { mador }\end{array}$ & $13124,2 \pm 8824,8$ & 0,004 & $29(74,4)$ & 0,280 & $8(66,7)$ & 0,648 \\
\hline & $\begin{array}{l}\text { Exfuma- } \\
\text { dor }\end{array}$ & $11313,4 \pm 8317,0$ & 0,382 & $4(10,3)$ & & $3(25,0)$ & \\
\hline & Fumador & $10493,1 \pm 9560,1$ & 0,010 & $6(15,4)$ & & $1(8,3)$ & \\
\hline \multirow{4}{*}{$\begin{array}{l}\text { Índice masa cor- } \\
\text { poral }\left(\mathrm{kg} / \mathrm{m}^{2}\right)\end{array}$} & $<18.5$ & $10484,7 \pm 5130,9$ & 0,889 & $0(0)$ & 9,535 & $0(0)$ & 1,000 \\
\hline & 18.5-24.9 & $11466,9 \pm 8439,6$ & 0,031 & $25(61)$ & & $8(66,7)$ & \\
\hline & 25.0-29.9 & $12349,7 \pm 7885,7$ & 0,536 & $8(19,5)$ & & $3(25)$ & \\
\hline & $\geq 30.0$ & $\begin{array}{l}17517,1 \pm \\
12717,7\end{array}$ & 0,014 & $8(19,5)$ & & $1(8,3)$ & \\
\hline
\end{tabular}




\begin{tabular}{|c|c|c|c|c|c|c|c|}
\hline Variables & $\begin{array}{l}\text { Cate- } \\
\text { gorías }\end{array}$ & IgG-Quant & $\mathrm{p}$-valor & $\lg M-S$ & $\mathrm{p}$-valor & $\begin{array}{l}\text { IgG-NP } \\
\text { n (\%) }\end{array}$ & $\mathrm{p}$-valor \\
\hline \multirow{2}{*}{$\begin{array}{l}\text { Toma algún } \\
\text { medicamento }\end{array}$} & Si & $12440,9 \pm 8720,8$ & 0,537 & $18(43,9)$ & 0,362 & $3(25)$ & 1,000 \\
\hline & No & $12132,2 \pm 9169,1$ & & $23(56,1)$ & & $9(75)$ & \\
\hline \multirow{2}{*}{ Toma vitaminas } & $\mathrm{Si}$ & $11971,2 \pm 9455,9$ & 0,724 & $6(14,6)$ & 1,000 & $4(33,3)$ & 1,000 \\
\hline & No & $12277,7 \pm 8958,1$ & & $35(85,4)$ & & $8(66,7)$ & \\
\hline \multirow{2}{*}{ Toma vitamina D } & $\mathrm{Si}$ & $13050,9 \pm 9360,5$ & 0,584 & $2(4,9)$ & 1,000 & $3(25)$ & 0,590 \\
\hline & No & $12176,8 \pm 9012,0$ & & $39(95,1)$ & & $9(75)$ & \\
\hline \multirow[t]{2}{*}{ Ocupación } & $\begin{array}{l}\text { Medicina } \\
\text { y Enfer- } \\
\text { mería }\end{array}$ & $12261,8 \pm 8279,0$ & 0,291 & $24(60)$ & 1,000 & $8(61,5)$ & 1,000 \\
\hline & Otras & $\begin{array}{c}12160,6 \pm \\
10001,2\end{array}$ & & $16(40)$ & & $5(38,5)$ & \\
\hline \multirow{2}{*}{$\begin{array}{l}\text { Padece alguna } \\
\text { enfermedad }\end{array}$} & $\mathrm{Si}$ & $12360,2 \pm 9189,0$ & 0,667 & $21(51,2)$ & 0,176 & $3(25)$ & 1,000 \\
\hline & No & $12168,0 \pm 8707,4$ & & $20(48,8)$ & & $9(75)$ & \\
\hline \multirow{2}{*}{$\begin{array}{l}\text { Enf. Endocri- } \\
\text { na-metabólica }\end{array}$} & $\mathrm{Si}$ & $13240,8 \pm 9340,4$ & 0,378 & $29(70,7)$ & 0,181 & $2(16,7)$ & 1,000 \\
\hline & No & $12064,0 \pm 8974,0$ & & $12(29,3)$ & & $\begin{array}{c}10 \\
(83,3)\end{array}$ & \\
\hline \multirow{2}{*}{$\begin{array}{l}\text { Exposición CO- } \\
\text { VID-19 }\end{array}$} & $\mathrm{Si}$ & $12636,1 \pm 9074,6$ & 0,284 & $26(63,4)$ & 1,000 & $12(100)$ & 0,093 \\
\hline & No & $11424,9 \pm 8900,7$ & & $15(36,6)$ & & $O(0)$ & \\
\hline \multirow{2}{*}{ Enf. COVID-19 } & $\mathrm{Si}$ & $22732,7 \pm 11120,1$ & 0,000 & $8(20)$ & 0,193 & $10(83,3)$ & 0,004 \\
\hline & No & $11202,4 \pm 8002.1$ & & $32(80)$ & & $2(16,7)$ & \\
\hline \multirow{2}{*}{ IgG-NP } & $\mathrm{Si}$ & $21933,5 \pm 12561,8$ & 0,005 & - & & - & \\
\hline & No & $11788,2 \pm 8598,2$ & & & & & \\
\hline \multirow{2}{*}{$\operatorname{lgM}-\mathrm{S}$} & $\mathrm{Si}$ & $17639,5 \pm 1042,5$ & 0,000 & - & & - & \\
\hline & No & $11283,2 \pm 8313,9$ & & & & & \\
\hline \multirow{2}{*}{$\begin{array}{l}\text { Efectos secun- } \\
\text { darios }\end{array}$} & Si & $12638,0 \pm 9189,4$ & 0,044 & $35(85,4)$ & 1,000 & $12(100)$ & 0,478 \\
\hline & No & $9612,4 \pm 7416,3$ & & $6(14,6)$ & & $0(0)$ & \\
\hline \multirow{2}{*}{$\begin{array}{l}\text { Efectos secunda- } \\
\text { rios tras } 1^{\text {a }} \text { dosis }\end{array}$} & Si & $11636,1 \pm 9074,6$ & 0,417 & $32(78)$ & 1,000 & $\begin{array}{c}11 \\
(91,7)\end{array}$ & 0,593 \\
\hline & No & $11424,9 \pm 8900,7$ & & $9(22)$ & & $1(8,3)$ & \\
\hline \multirow{2}{*}{$\begin{array}{l}\text { Efectos secunda- } \\
\text { rios tras } 2^{\text {a }} \text { dosis }\end{array}$} & Si & $22732,7 \pm 11120,1$ & 0,024 & $33(80,5)$ & 1,000 & $\begin{array}{c}11 \\
(91,7)\end{array}$ & 0,593 \\
\hline & No & $11202,4 \pm 8002,1$ & & $8(19,5)$ & & $1(8,3)$ & \\
\hline
\end{tabular}

En el análisis multivariante ajustado para cada variable independiente (Tabla 3), la tasa de IgG-Quant aumentaba de forma significativa a mayor IMC, en la obesidad $\left(\mathrm{IMC} \geq 30,0 \mathrm{~kg} / \mathrm{m}^{2}\right)$, en no fumadores, y en los $\mathrm{lgM}$-S y/o lgG-NP positivos. 
Tabla 3. Análisis de las asociaciones entre la prevalencia de anticuerpos anti-SARS-CoV-2 (IgG-Quant) y las diferentes variables independientes.

\begin{tabular}{|c|c|c|c|c|c|c|}
\hline \multirow{2}{*}{ Variables } & \multicolumn{3}{|c|}{ Análisis univariante } & \multicolumn{3}{|c|}{ Análisis multivariante } \\
\hline & $\mathrm{CR}$ & $95 \%$ IC & $\mathrm{p}$-valor & $\mathrm{CR}$ & $95 \%$ IC & p-valor \\
\hline Edad (años) & $-30,2$ & $-528,2-67,8$ & 0,545 & $-27,2^{\mathrm{a}}$ & $-125,6-71,2$ & 0,587 \\
\hline Sexo (Varón) & 991,8 & $\begin{array}{c}-1467,7- \\
3451,5 \\
\end{array}$ & 0,428 & $919,2^{\mathrm{a}}$ & $\begin{array}{c}-1589,3- \\
3407,9 \\
\end{array}$ & 0,474 \\
\hline $\begin{array}{l}\text { Indice masa corporal } \\
(\mathrm{IMC})(\mathrm{Kg} / \mathrm{m} 2)\end{array}$ & 292,8 & $44,2-541,5$ & 0,021 & $359,5^{b}$ & $82,7-636,4$ & 0,011 \\
\hline IMC (4 grupos) ${ }^{\mathrm{C}}$ & 2358,0 & $\begin{array}{c}900,1 \\
-3811,8 \\
\end{array}$ & 0,002 & $2780,4^{b}$ & $\begin{array}{r}1188,4 \\
-4372,3 \\
\end{array}$ & 0,001 \\
\hline$I M C \geq 30 \mathrm{~kg} / \mathrm{m}^{2}$ & 5800,0 & $\begin{array}{l}2556,2- \\
9043,7\end{array}$ & 0,001 & $6260,5^{b}$ & $\begin{array}{l}2807,7- \\
9713,3\end{array}$ & 0,000 \\
\hline No fumador & 2231,4 & $84,7-4378,1$ & 0,042 & $2414,3^{d}$ & $73,2-4755,4$ & 0,043 \\
\hline $\begin{array}{l}\text { Consu- Exfumador } \\
\text { mo de }\end{array}$ & $-1069,6$ & $\begin{array}{c}-3693,4- \\
1554,2 \\
\end{array}$ & 0,423 & $-1622,0^{d}$ & $\begin{array}{c}-4525,5- \\
1281,4 \\
\end{array}$ & 0,272 \\
\hline tabaco Fumador & $-2139,6$ & $\begin{array}{c}-4705,4- \\
426,2\end{array}$ & 0,102 & $-1778,5^{d}$ & $\begin{array}{c}-4480,7- \\
923,7\end{array}$ & 0,196 \\
\hline Consumo alcohol & 674,5 & $\begin{array}{r}-1510,9- \\
2868,0 \\
\end{array}$ & 0,544 & $969,1^{e}$ & $\begin{array}{c}-1300,8- \\
3239,0 \\
\end{array}$ & 0,409 \\
\hline Ejercicio & $-1008,8$ & $\begin{array}{c}-3198,4- \\
1180,8\end{array}$ & 0,365 & $-1643,4^{f}$ & $\begin{array}{c}-3908,3- \\
622,2\end{array}$ & 0,154 \\
\hline Toma algún medicamento & 312,67 & $\begin{array}{l}-2008,2 \\
-2633,5 \\
\end{array}$ & 0.791 & $439,8^{9}$ & $\begin{array}{l}-2081,2 \\
-2960,9 \\
\end{array}$ & 0,731 \\
\hline Toma vitaminas & $-306,5$ & $\begin{array}{l}-3288,1- \\
2697,1 \\
\end{array}$ & 0,840 & $-717,7^{9}$ & $\begin{array}{l}-3773,0- \\
2337,8 \\
\end{array}$ & 0,644 \\
\hline Toma vitamina D & 840,0 & $\begin{array}{l}-3578,7- \\
5326,8\end{array}$ & 0,699 & $1376,4^{9}$ & $\begin{array}{c}-3134,0- \\
5892,5\end{array}$ & 0,549 \\
\hline $\begin{array}{l}\text { Ocupación Medicina + } \\
\text { Enfermería }\end{array}$ & 95,2 & $\begin{array}{l}-2094,5- \\
2284,8\end{array}$ & 0,932 & $115,6^{h}$ & $\begin{array}{l}-2392,0- \\
2161,8\end{array}$ & 0,920 \\
\hline Padecer enfermedad & 192,3 & $\begin{array}{c}-2093,6- \\
2478,2 \\
\end{array}$ & 0,864 & 84 & $\begin{array}{l}-2494,4- \\
2326,4 \\
\end{array}$ & 0,945 \\
\hline Enf. Endocrina-metabólica & 1576,8 & $\begin{array}{c}-1894,6- \\
4248,3 \\
\end{array}$ & 0,541 & 2040,8 & $\begin{array}{c}-1214,9- \\
5296,5 \\
\end{array}$ & 0,218 \\
\hline $\operatorname{lgG}-N P$ & 10145,3 & $\begin{array}{l}5035,7- \\
15258,0 \\
\end{array}$ & 0,000 & 10243,9 & $\begin{array}{l}5097,8- \\
15389,7 \\
\end{array}$ & 0,000 \\
\hline $\operatorname{lgM}-\mathrm{S}$ & 6356,3 & $\begin{array}{l}3441,6- \\
9271,0\end{array}$ & 0,000 & $5605,9^{k}$ & $\begin{array}{l}2487,0- \\
8724,8\end{array}$ & 0,000 \\
\hline
\end{tabular}

CR: Coeficiente de regresión. (a) Ajustado por sexo/ edad. (b) Ajustado por edad, sexo, ocupación, alcohol, tabaco, ejercicio físico, vitamina D. (c) Grupos $<18,5,18,5-24,9,25-29,9, \geq 30 \mathrm{~kg} / \mathrm{m} 2$. (d-e) Ajustado por edad, sexo, ocupación, alcohol, ejercicio físico, vitamina D. (f) Ajustado por edad, sexo, ocupación, tabaco, alcohol vitamina D. (g) Ajustado por edad, sexo, ocupación, tabaco, alcohol, ejercicio físico. (h) Ajustado por edad, sexo. (i) Ajustado por edad, sexo, alcohol, tabaco, ejercicio físico, vitamina D, IMC. (j-k) Ajustado por edad, sexo, enfermedad, alcohol, tabaco, ejercicio físico, IMC y vitamina D

La prevalencia de anticuerpos IgM-S (Tabla 4) se asociaba significativamente con ser varón, no-fumador, presentar enfermedad endocrino-metabólica, haber pasado la COVID-19 y tener anticuerpos IgG-NP. 
Tabla 4. Análisis de las asociaciones (Riesgo Relativo simple .RR-y ajustado-RRa-)entre presencia de anticuerpos anti-SARS-CoV-2 (IgM-S) y las diferentes variables como variables independientes.

\begin{tabular}{|c|c|c|c|c|c|c|}
\hline \multirow{2}{*}{ Variables } & & \multicolumn{3}{|c|}{ Análisis univariante } & \multicolumn{2}{|c|}{ Análisis multivariante } \\
\hline & & $\begin{array}{l}\operatorname{lgM}-\mathrm{S}(+) \\
\mathrm{N}=41(\%)\end{array}$ & $\begin{array}{l}\operatorname{lgM}-S(-) \\
\mathrm{N}=234(\%)\end{array}$ & $\begin{array}{l}\text { RR }(95 \% \\
\text { IC ) }\end{array}$ & $\begin{array}{l}\mathrm{RRa}(95 \% \\
\mathrm{IC})\end{array}$ & p-valor \\
\hline \multicolumn{2}{|c|}{$\begin{array}{l}\text { Edad (años) } \pm \text { desviación } \\
\text { estándar }\end{array}$} & $43,6 \pm 10,7$ & $44,8 \pm 11,2$ & $\begin{array}{l}0,99(0,97- \\
1,02)\end{array}$ & $\begin{array}{l}0,99(0,97- \\
1,02)^{\mathrm{a}}\end{array}$ & 0,696 \\
\hline \multirow[t]{2}{*}{ Sexo } & Varón & $17(41,5)$ & $53(22,6)$ & $\begin{array}{l}2,07(1,18- \\
3,63)\end{array}$ & $\begin{array}{l}1,93(1,08- \\
3,43)^{b}\end{array}$ & 0,026 \\
\hline & Mujer & $24(58,5)$ & $181(77,4)$ & 1,00 & & \\
\hline \multirow{5}{*}{$\begin{array}{l}\text { Índice masa corpo- } \\
\text { ral (IMC) }\end{array}$} & & $25,2 \pm 4,3$ & $24,7 \pm 4,4$ & $\begin{array}{l}1,02(0,96- \\
1,08)\end{array}$ & $\begin{array}{l}1,03(0,95- \\
1,11)^{\mathrm{b}}\end{array}$ & 0,501 \\
\hline & $\begin{array}{l}<18.5 \mathrm{~kg} / \\
\mathrm{m}^{2}\end{array}$ & 0 & $6(2,7)$ & 1,00 & & \\
\hline & $18.5-24.9$ & $25(61)$ & $130(57,5)$ & $\begin{array}{l}1,38(0,24- \\
\infty)\end{array}$ & & \\
\hline & 25.0-29.9 & $8(19,5)$ & $65(28,8)$ & $\begin{array}{l}0,91(0,14- \\
\infty)\end{array}$ & & \\
\hline & $\geq 30.0$ & $8(19,5)$ & $25(11,1)$ & $\begin{array}{l}2,01(0,31- \\
\infty)\end{array}$ & $\begin{array}{l}1,61(0,72- \\
3.63)^{b}\end{array}$ & 0,245 \\
\hline \multirow{3}{*}{$\begin{array}{l}\text { Consumo de } \\
\text { tabaco }\end{array}$} & $\begin{array}{l}\text { No fuma- } \\
\text { dor }\end{array}$ & $29(70,7)$ & $124(53,7)$ & $\begin{array}{l}2,22(1,13- \\
4,37)\end{array}$ & $\begin{array}{l}2,54(1,19- \\
5.39)^{\mathrm{c}}\end{array}$ & 0,016 \\
\hline & Exfumador & $4(9,8)$ & $53(22,9)$ & $\begin{array}{l}0,43(0,15- \\
1,15)\end{array}$ & $\begin{array}{l}0,48(0,18- \\
1,30)^{c}\end{array}$ & 0,148 \\
\hline & Fumador & $6(14,6)$ & $54(23,4)$ & $\begin{array}{l}0,64(0,28- \\
1,45)\end{array}$ & $\begin{array}{l}0,42(0,16- \\
1,09)^{c}\end{array}$ & 0,074 \\
\hline \multirow[t]{2}{*}{ Consumo alcohol } & $\mathrm{Si}$ & $25(61)$ & $133(57,3)$ & $\begin{array}{l}1,74(0,63- \\
2,03)\end{array}$ & $\begin{array}{l}1,10(0,59- \\
1,90)^{\mathrm{d}}\end{array}$ & 0,757 \\
\hline & No & $16(39)$ & $99(42,7)$ & 1,00 & & \\
\hline \multirow[t]{2}{*}{ Ejercicio habitual } & Si & $27(65,9)$ & $139(59,4)$ & $\begin{array}{l}1,31(0,70- \\
2,31)\end{array}$ & $\begin{array}{l}1,25(0,66- \\
2,37)^{e}\end{array}$ & 0,490 \\
\hline & No & $14(34,1)$ & $95(40,6)$ & 1,00 & & \\
\hline \multirow{2}{*}{$\begin{array}{l}\text { Toma algún medi- } \\
\text { camento }\end{array}$} & $\mathrm{Si}$ & $18(43,9)$ & $67(28,6)$ & $\begin{array}{l}1,75(0.99- \\
3.07)\end{array}$ & $\begin{array}{l}1,60(0,39- \\
2,92)^{h}\end{array}$ & 0,906 \\
\hline & No & $23(56,1)$ & $\begin{array}{l}167 \\
(71,4)\end{array}$ & & & \\
\hline \multirow{2}{*}{ Toma vitaminas } & Si & $6(14,6)$ & $36(15,4)$ & $\begin{array}{l}0,95(0,43- \\
2,12)\end{array}$ & $\begin{array}{l}1,03(0.28- \\
3,83)^{\dagger}\end{array}$ & 0,957 \\
\hline & No & $35(85,4)$ & $198(84,6)$ & & & \\
\hline \multirow{2}{*}{ Toma vitamina D } & $\mathrm{Si}$ & $2(4,9)$ & $15(6,4)$ & $\begin{array}{l}0,78(0.20- \\
2.96)\end{array}$ & $\begin{array}{l}1,06(0,41- \\
2,52)^{\dagger}\end{array}$ & 0,972 \\
\hline & No & $39(95,1)$ & $219(93,6)$ & & & \\
\hline \multirow{2}{*}{ Ocupación } & $\begin{array}{l}\text { Medicina + } \\
\text { Enfermería }\end{array}$ & $24(60)$ & $132(57,1)$ & $\begin{array}{l}1,11(0,62- \\
1,99)\end{array}$ & $\begin{array}{l}1,11(0,60- \\
2,03)^{9}\end{array}$ & 0,746 \\
\hline & Otras & $16(40)$ & $99(42,9)$ & 1,00 & & \\
\hline
\end{tabular}




\begin{tabular}{|c|c|c|c|c|c|c|}
\hline \multirow{2}{*}{ Variables } & & \multicolumn{3}{|c|}{ Análisis univariante } & \multicolumn{2}{|c|}{ Análisis multivariante } \\
\hline & & $\begin{array}{l}\operatorname{lgM}-\mathrm{S}(+) \\
\mathrm{N}=41(\%)\end{array}$ & $\begin{array}{l}\operatorname{lgM}-\mathrm{S}(-) \\
\mathrm{N}=234(\%)\end{array}$ & $\begin{array}{l}\text { RR }(95 \% \\
\text { IC ) }\end{array}$ & $\begin{array}{l}\mathrm{RRa}(95 \% \\
\text { IC) }\end{array}$ & p-valor \\
\hline \multirow{2}{*}{$\begin{array}{l}\text { Padecer alguna } \\
\text { enfermedad }\end{array}$} & Si & $21(51,2)$ & $71(30,3)$ & $\begin{array}{l}2,09(1,19- \\
3,66)\end{array}$ & $\begin{array}{l}2,39(1,28- \\
4,47)^{\mathrm{h}}\end{array}$ & 0,006 \\
\hline & No & $20(48,8)$ & $163(69,7)$ & 1,00 & & \\
\hline \multirow{2}{*}{$\begin{array}{l}\text { Enf. Endocrino-me- } \\
\text { tabólica }\end{array}$} & Si & $12(29,3)$ & $27(11,5)$ & $\begin{array}{l}2,50(1,40- \\
4,48)\end{array}$ & $\begin{array}{l}3,20(1,68- \\
6,10)^{\mathrm{h}}\end{array}$ & 0,000 \\
\hline & No & $29(70,7)$ & $207(88,5)$ & 1,00 & & \\
\hline \multirow[t]{2}{*}{ Expo. COVID-19 } & Si & $26(63,4)$ & $157(67,1)$ & $\begin{array}{l}0,87(0,49- \\
1,56)\end{array}$ & & \\
\hline & No & $15(36,6)$ & $77(32,9)$ & 1,00 & & \\
\hline \multirow[t]{2}{*}{ Enf. COVID-19 } & Si & $8(20)$ & $15(6,4)$ & $\begin{array}{l}2,72(1,08- \\
6,92)\end{array}$ & $\begin{array}{l}2,95(1,56- \\
5,60)^{i}\end{array}$ & 0,001 \\
\hline & No & $32(80)$ & $218(93,6)$ & 1,00 & & \\
\hline IgG-NP & & $6(14,6)$ & $7(3,0)$ & $\begin{array}{l}3,45(1,78- \\
6,71)\end{array}$ & $\begin{array}{l}3,22(1,76- \\
5,91)^{j}\end{array}$ & 0,000 \\
\hline
\end{tabular}

RR= Riesgo Relativo, RRa = Riesgo Relativo ajustado por regresión de Poisson robusta con 95\% Intervalo de confianza (IC). (a) Ajustado por sexo, edad. (b) Ajustado por edad, sexo, ocupación, alcohol, tabaco, ejercicio físico, vitamina D. (c) Ajustado por edad, sexo, ocupación, alcohol, ejercicio físico, vitamina D. (d) Ajustado por edad, sexo, ocupación, tabaco, ejercicio físico, vitamina D. (e) Ajustado por edad, sexo, ocupación, tabaco, alcohol, vitamina D. (f) Ajustado por edad, sexo, ocupación, ejercicio físico, alcohol, tabaco. (g) Ajustado por edad sexo. (h-i) Ajustado por edad, sexo, alcohol, tabaco, ejercicio físico, IMC, vitamina D. (j) Ajustado por edad, sexo, enfermedad, alcohol, tabaco, ejercicio físico, IMC, vitamina D

A partir de los resultados de anticuerpos IgG-Quant, IgM-S, e IgG-NP se compararon cuatro grupos serológicos (Tabla 5): Grupo 1 de participantes con solo IgGQuant y un participante negativo ( $n=227)$, Grupo 2 de participantes con IgG-Quant e IgM-S ( $n=36)$, Grupo 3 los que tenían IgG-Quant e IgG-NP ( $n=7$ ) y Grupo 4 los que tenían IgG-Quant, IgM-S e IgG-NP ( $n=5)$. El Grupo 4 alcanzó tasas significativamente más elevadas de IgG-Quant debido a una mayor exposición y enfermedad por COVID-19; así mismo se apreció mayor prevalencia de enfermedad incluyendo la endocrino-metabólica y el tomar vitamina D. Comparando con el Grupo 1, los niveles de IgG-Quant fueron 2,74 veces más elevados (22.837.7 UA/ml versus $8,317,0 \cup \mathrm{UA} / \mathrm{ml})$.

Con estos cuatro grupos se realizó un análisis de la varianza con IgG-Quant como variable dependiente y la edad estratificada en 6 grupos, el sexo, la obesidad $(\mathrm{IMC}>=30.0 \mathrm{Kg} / \mathrm{m} 2)$ y no fumador como variables independientes. En el modelo predictivo (Figura 1), el Grupo 4 alcanzó los niveles mayores de IgG-Quant con la obesidad y no fumador, observándose un descenso progresivo hasta el Grupo 1. Este modelo explicaba un 18,43\% ( $p=0.000)$ de la varianza de IgG-Quant entre los grupos. 
Tabla 5. Comparación de los grupos serológicos según las variables independientes

\begin{tabular}{|c|c|c|c|c|c|c|}
\hline \multicolumn{2}{|l|}{ Variables } & $\begin{array}{c}\text { Grupo } 1 \\
\mathrm{~N}=227 \\
\mathrm{~N}(\%)\end{array}$ & $\begin{array}{c}\text { Grupo } 2 \\
\mathrm{~N}=36 \\
\mathrm{~N}(\%)\end{array}$ & $\begin{array}{c}\text { Grupo } 3 \\
N=7 \\
N(\%)\end{array}$ & $\begin{array}{c}\text { Grupo } 4 \\
N=5 \\
N(\%)\end{array}$ & p-valor \\
\hline \multicolumn{2}{|l|}{ Sexo Varón } & $51(22,5)$ & $15(41,7)$ & $2(28,6)$ & $2(40)$ & 0,062 \\
\hline \multicolumn{2}{|l|}{ Edad } & $44.8 \pm 11.2$ & $43.9 \pm 10.9$ & $43.1 \pm 9.8$ & $41.4 \pm 9.6$ & 0,853 \\
\hline \multicolumn{2}{|l|}{$\mid g G$-Quant UA/m|a } & 8317,0 & 13274,0 & 14281,4 & 22837,7 & 0,001 \\
\hline \multicolumn{2}{|c|}{$95 \%$ IC IgG-Quant UA/m| } & $\begin{array}{l}7357,0- \\
9402,3\end{array}$ & $\begin{array}{l}10333,2- \\
17051,8\end{array}$ & $\begin{array}{l}6271,8- \\
32520,0\end{array}$ & $\begin{array}{l}9686,3- \\
53845,0\end{array}$ & \\
\hline \multicolumn{2}{|l|}{ Exposición-COVID-19 } & $150(66,1)$ & $21(58,3)$ & $7(100)$ & $5(100)$ & 0,002 \\
\hline \multicolumn{2}{|c|}{ Enfermefdad-COVID-19 } & $10(4,4)$ & $3(8,6)$ & $5(71,4)$ & $5(100)$ & 0,000 \\
\hline \multicolumn{2}{|c|}{ Padece alguna enfermedad } & $70(30,8)$ & $17(47,7)$ & $0(0)$ & $3(60)$ & 0,023 \\
\hline \multicolumn{2}{|c|}{ Enfermedad endocrino-metabólica } & $26(11,5)$ & $10(27,8)$ & $0(0)$ & $2(40)$ & 0,017 \\
\hline \multirow{3}{*}{ Consumo tabaco } & No fumador & $120(53,6)$ & $25(73,5)$ & $4(57,1)$ & $4(80)$ & \multirow{3}{*}{0,155} \\
\hline & Exfumador & $50(22,3)$ & $4(11,8)$ & $3(42,9)$ & $0(0)$ & \\
\hline & Fumador & $54(24,1)$ & $5(14,7)$ & $0(0)$ & $1(20)$ & \\
\hline \multicolumn{2}{|l|}{ Toma fármacos } & $65(20,6)$ & $16(44,4)$ & $2(28,6)$ & $2(40)$ & 0,233 \\
\hline \multicolumn{2}{|l|}{ Toma vitaminas } & $34(15)$ & $5(13,9)$ & $2(28,6)$ & $1(20)$ & 0,564 \\
\hline \multicolumn{2}{|l|}{ Toma vitamina D } & $13(5,73)$ & $1(2,8)$ & $2(28,6)$ & $1(20)$ & 0,042 \\
\hline \multicolumn{2}{|l|}{ Consumo alcohol } & $129(57,3)$ & $24(66,7)$ & $4(57,1)$ & $2(33,3)$ & 0,249 \\
\hline \multicolumn{2}{|l|}{ Ejercicio habitual } & $134(59)$ & $22(61,1)$ & $5(71,4)$ & $6(100)$ & 0,320 \\
\hline \multirow{5}{*}{$\begin{array}{l}\text { Índice masa corpo- } \\
\text { ral (IMC) kg/m2 }\end{array}$} & & $24.7 \pm 4.4$ & $25.3 \pm 4.2$ & $24.2 \pm 3.4$ & $24.5 \pm 5.4$ & 0,834 \\
\hline & $<18.5$ & $6(2,7)$ & $0(0)$ & $0(0)$ & $0(0)$ & \multirow{4}{*}{0,644} \\
\hline & $18.5-24.9$ & $126(57,5)$ & $21(58,3)$ & $4(57,1)$ & $4(80)$ & \\
\hline & 25.0-29.9 & $62(28,3)$ & $8(22,2)$ & $3(42,9)$ & $0(0)$ & \\
\hline & $\geq 30.0$ & $25(11,4)$ & $7(19,4)$ & $0(0)$ & $1(20)$ & \\
\hline
\end{tabular}

Grupo 1 (solo positivos IgG-Quant + 1 negativo) Grupo 2 (solo positivos IgG-Quant + IgM-S) Grupo 3 (solo positivos IgG-Quant + IgG-NP) Grupo 4 (sólo positivos IgG-Quant + IgG-NP + IgM-S).

(a) Media geométrica IgG-Quant

(b) $95 \%$ Intervalo confianza (IC).

Respecto a los efectos secundarios, presentaron algún síntoma después de la vacunación el 86,5\% (238/275) (95\% IC 81,9-90.3) de los participantes; siendo los afectados con la primera dosis $211(76,7 \%)$ (95\% IC 71,3-81,5), y en la segunda 217 (95\% IC 73,6-83,6). Los más frecuentes tras la primera dosis fueron: dolor en el brazo $(92,9 \%)$, hinchazón $(16,6 \%)$, cefaleas $(16,6 \%)$, mialgias $(12,3 \%)$, fatiga (11.9\%), enrojecimiento $(10,4 \%$ y yiebre $(4,3 \%)$. Sólo los dos últimos se asociaban con mayores niveles de anticuerpos IgG-Quant.

Tras la segunda dosis, los predominantes fueron dolor en el brazo (79,9\%), cefaleas (35,5\%), mialgias (31,8\%), fatiga (25,8\%), fiebre $(21,2 \%)$, artralgias $(18,4 \%)$ y mareos $(11,5 \%)$. Se asociaban a mayores niveles de anticuerpos IgG-Quant la presencia de mialgias, artralgias, fiebre y mareos. Ningún trabajador requirió atención médica. 


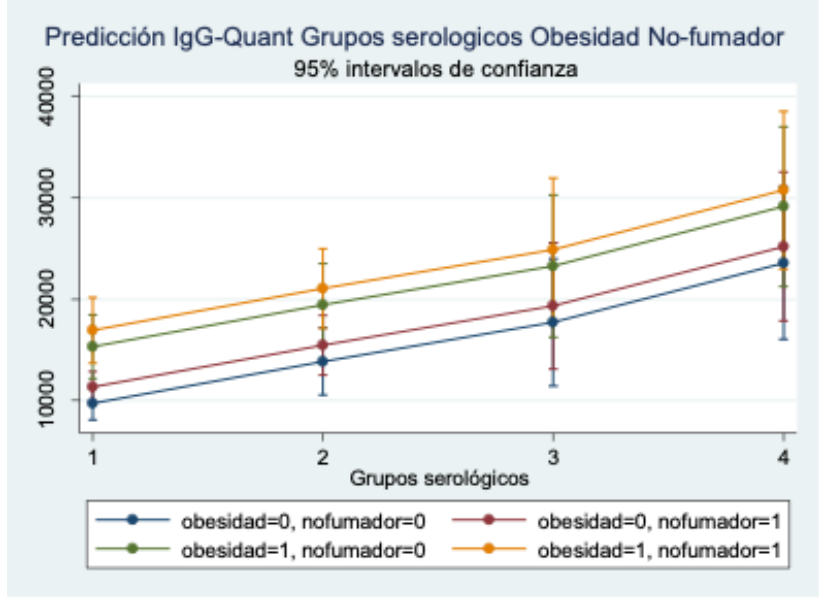

Figura 1. Predicción de los niveles de IgG-Quant en función de los 4 grupos serológicos, obesidad (IMC $\geq 30.0$ kg/m2), no fumador, ajustado por edad y sexo. Los grupos serológicos son: Grupo 1 (solo positivos IgG-Quant + un negativo) Grupo 2 (solo positivos IgG-Quant + IgM-S) Grupo 3 (solo positivos IgG-Quant + IgG-NP) Grupo 4 (sólo positivos IgG-Quant + IgG-NP + IgM-S).

Mediante un análisis de regresión de Poisson se compararon los participantes con síntomas de aquellos que no los sufrieron. Los efectos secundarios fueron significativamente mayores en jóvenes, mujeres, los que tenían IgG-NP positivos, y a mayores niveles de IgG-Quant. Considerando los 4 grupos serológicos, se apreció un incremento significativo de IgG-Quant desde el primer grupo al cuarto, ajustado por edad y sexo (datos no mostrados).

\section{Discusión}

Los resultados obtenidos muestran que el $99.6 \%$ de los participantes presentaron anticuerpos IgG-Quant, estos datos sugieren que la vacuna ofrece una protección muy elevada en personal de alto riesgo. La única persona que no creó anticuerpos estaba bajo tratamiento inmunosupresor.

En relación a los niveles de anticuerpos, en el análisis univariante, nuestros resultados concuerdan con los de otros autores, cómo Müller et al(18) que detectan una respuesta de anticuerpos menor en el grupo de pacientes de mayor edad. Así mismo, un estudio en Israel(19), concluye que también tienen menos anticuerpos los de mayor edad. Estudios en fase II de las vacunas ya sugerían una menor respuesta en gente mayor en comparación con los más jóvenes ${ }^{(20)}$.

Se había descrito ${ }^{(21,22)}$ que el tabaquismo podría ser un factor de severidad de la COVID-19, pero se han publicado pocos trabajos que relacionen al tabaquismo con una menor respuesta a la vacuna. En este estudio los no fumadores generaron más anticuerpos, que los fumadores. Estos resultados coinciden con los de Watanabe y co-autores ${ }^{(23)}$. 
En general, en enfermos de COVID-19 se ha observado que a mayor IMC corresponde un nivel más elevado de anticuerpos-SARS-CoV-2 ${ }^{(24,25)}$. Pellini y co-autores ${ }^{(26)}$ estudiando personas sólo vacunadas no hallaron asociación entre el IMC y los niveles de IgG-Quant y Watanabe y co-autores ${ }^{(23)}$ encontraron que a mayor obesidad abdominal había menores niveles de IgG-Quant. En nuestro estudio excluyendo los participantes con historia previa de COVID-19 y mediante análisis multivariante, la obesidad, y el IMC distribuido en 4 grupos incrementaban significativamente los niveles de IgG-Quant. No obstante, en pacientes obesos este incremento de IgG-Quant se precisaría determinar si protege adecuadamente contra la enfermedad ${ }^{(27) .}$ Estudios con muestras más amplias serían necesarios para confirmar estos resultados.

Los niveles de IgG-Quant alcanzados por los participantes previamente infectados por SARS-CoV-2, fueron significativamente más elevados que los no-infectados en línea con otras publicaciones ${ }^{(28,29)}$. Algunos estudios encontraron qué con la primera dosis de vacunación, se alcanzaban los niveles de los no-infectados vacunados con dos dosis, y que la segunda dosis en infectados no producía un aumento sustancial de IgG-Quant. Se sugería que una sola dosis podría ser suficiente para obtener inmunidad frente al virus en una situación de escasez de vacuna y de pandemia ${ }^{(19,30,31)}$.

Se detectó IgM-S, como en otros estudios, en algunas personas vacunadas que no habían sufrido la enfermedad ${ }^{(10)}$. En nuestro caso encontramos varias variables asociadas a su presencia. Sin embargo, no hemos encontrado otras referencias respecto a estas variables, salvo en un estudio en pacientes de COVID-19 en que observaron mayores niveles de anticuerpos totales $S(\lg G+\operatorname{lgM})$ en no fumadores $^{(32)}$. Pensamos que la determinación de IgM-S no se debe utilizar en vacunados para diagnosticar enfermedad aguda porque podría llevar a confusión.

La prevalencia de IgG-NP fue más baja que en otros estudios sobre personal sanitario en España ${ }^{(14,15)}$ y se apreció que en casi la mitad de los casos COVID-19 confirmados no se detectaron IgG-NP, probablemente relacionado con el declive de la inmunidad humoral y con las técnicas utilizadas ${ }^{(33)}$.

Como ya se ha descrito(12,13), los efectos secundarios son más frecuentes tras la segunda dosis de la vacuna y se asocian con niveles más altos de IgG-Quant ${ }^{(34)}$.

Dada la eficacia de las vacunas que se han utilizado, en el momento actual no se recomienda comprobar la respuesta inmunitaria mediante la medición de anticuerpos $^{(35)}$, nuestros datos también lo avalan. La determinación de personas vulnerables frente a la infección una vez vacunados y en un medio laboral con inmunización postvacunal masiva, ha de ser estudiada de forma individual sin poder aplicar normas generales. Si bien se considerará la edad, la presencia de enfermedades crónicas, mujeres en edad gestacional y trabajadores de sectores laborales que impliquen mayores riesgos, como ocurre con el personal sanitario o dedicado a la atención de mayores o discapacitados.

El estudio presenta las siguientes fortalezas: 1) se ha basado en una muestra representativa de todo el personal del hospital con una participación muy elevada, 2) 
las pruebas serológicas utilizadas tienen una alta sensibilidad y especificidad y 3) Se emplearon análisis multivariantes para controlar factores de confusión.

Entre las limitaciones se pueden indicar las siguientes: 1) no evaluamos la inmunidad celular que también participa en la respuesta inmunitaria ni realizamos ensayos de anticuerpos neutralizantes, 2) el tamaño de la muestra es limitado para obtener conclusiones definitivas de los anticuerpos IgG-NP y IgM-S, 3) nuestros resultados no serían extrapolables a la población general tanto por la edad como por el mayor riesgo de exposición que presenta el colectivo estudiado a la enfermedad y 4) al tratarse de un nuevo virus hay muchos aspectos de este que todavía desconocemos y por tanto podrían existir otros factores que podrían estar influyendo nuestros resultados sin que hayan sido analizados.

Sería conveniente considerar el seguimiento de esta cohorte de trabajadores vacunados, para conocer con mayor precisión la dinámica de la inmunidad que confiere la vacuna y su permanencia en el tiempo con vistas a posteriores revacunaciones. Así mismo sería crucial determinar el nivel de anticuerpos IgG que protegen frente a la enfermedad, su duración y factores asociados.

\section{Conclusiones}

Todos los participantes desarrollaron una respuesta de inmunidad humoral, excepto uno. Las variables relacionadas con presentar niveles de anticuerpos elevados fueron: haber padecido la enfermedad previamente, IMC $>30$, ser no fumador, y la positividad a IgM-S y/o IgG-NP. Un porcentaje alto desarrolló efectos secundarios leves, y eran más frecuentes en los que habían padecido la enfermedad.

\section{Agradecimientos}

Damos las gracias al personal del Hospital General Universitario de Castellón que con su gran participación hizo posible este estudio.

\section{Financiación}

Los autores declaran que no han recibido financiación para la autoría y/o publicación de este artículo.

\section{Conflicto de intereses}

Los autores declaran que no existen conflictos de intereses en la autoría y/o publicación de este artículo 


\section{Bibliografía}

1. Reina J. El SARS-CoV-2, una nueva zoonosis pandémica que amenaza al mundo. Vacunas. 2020;21(1):17-22. doi:10.1016/j.vacun.2020.03.001.

2. Ullah H, Ullah A, Gull A, Mousavi T, Khan MW. Novel Coronavirus 2019 (COVID-19) Pandemic Outbreak: A Comprehensive Review of the Current Literature. Vacunas. 2021;22(2):106-113.

3. Médicos Sin Fronteras. Informe sobre la protección del personal sanitario durante la COVID-19 en España. Barcelona: Médicos Sin Fronteras; 2020 [citado 25 Ago 2021]. Disponible en: https://www.msf.es/sites/default/files/documents/ msf-informe-covid19-proteccion-web01.pdf

4. Instituto de Salud Carlos III, Centro Nacional de Epidemiología, Red Nacional de Vigilancia Epidemiológica. Análisis de los casos de COVID-19 en personal sanitario notificados a la Red Nacional de Vigilancia Epidemiológica (RENAVE) hasta el 10 de mayo en España. 2020 [citado 25 Ago 2021]. Disponible en: https://www.isciii. es/QueHacemos/Servicios/VigilanciaSaludPublicaRENAVE/EnfermedadesTransmisibles/Documents/INFORMES/Informes\%20COVID-19/COVID-19\%20en\%20 personal\%20sanitario\%2029\%20de\%20mayo\%20de\%202020.pdf

5. Amit S, Regev-Yochay G, Afek A, Kreiss Y, Leshem E. Early rate reductions of SARS-CoV-2 infection and COVID-19 in BNT162b2 vaccine recipients. Lancet. 2021;397(10277):875-877.

6. Belete TM. A review on Promising vaccine development progress for COVID-19 disease. Vacunas. 2020;21(2):121-128.

7. Camara C, Lozano-Ojalvo D, Lopez-Granados E, Paz-Artal E, Pion M, Rafael Correa-Rocha $R$, et al. Differential effects of the second SARS-CoV-2 mRNA vaccine dose on T cell immunity in naïve and COVID-19 recovered individuals. Cell Rep. 2021;36(8):109570.

8. Sharma O, Sultan AA, Ding H, Triggle CR. A review of the progress and challenges of developing a vaccine for COVID-19. Front Immunol. 2020;11:585354.

9. Polack FP, Thomas SJ, Kitchin N, AbsalonJ, Gurtman A, Lockhart S, et al. Safety and efficacy of the BNT162b2 mRNA Covid-19 Vaccine. N Engl J Med. 2020;383(27):2603-2615.

10. Narasimhan $M$, Mahimainathan $L$, Araj E, Clark AE, Markantonis J, Green A, Xu $J$ et al. Clinical evaluation of the Abbott Alinity SARS-CoV-2 spike-specific quantitative IgG and IgM assays among infected, recovered, and vaccinated groups. J Clin Microbiol. 2021;59(7):e0038821.

11. Epi Info version 7. Atlanta: Centers for Disease Control and Prevention 2013. [citado 25 Ago 2021]. Disponible en: https://www.cdc.gov/epiinfo

12. Polack FP, Thomas SJ, Kitchin N, Absalon J, Gurtman A, Lockhart S, et al. Safety and efficacy of the BNT162b2 mRNA Covid-19 vaccine. N Engl J Med. 2020;383(27):2603-2615. 
13. Oliver SE, Gargano JW, Marin M, Wallace M, Curran KG, Chamberland M, et al. The Advisory Committee on Immunization Practices' Interim recommendation for use of Pfizer-BioNTech COVID-19 Vaccine. MMWR Morb Mortal Wkly Rep. 2020;69(50):1922-1924.

14. Varona JF, Madurga R, Peñalver F, Abarca E, Almirall C, Cruz, et al. Seroprevalence of SARS-CoV-2 antibodies in over 6000 healthcare workers in Spain. Int J Epidemiol. 2021;50(2):400-409.

15. Barallat J,Fernández-Rivas G, Quirant-Sánchez B, González V, Doladé M, Martinez-Caceres E, et al. Seroprevalence of SARS-CoV-2 IgG specific antibodies among healthcare workers in the Northern Metropolitan Area of Barcelona, Spain, after the first pandemic wave. PLoS One. 2020;15(12):e0244348.

16. Dean AG, Sullivan KM, Soe MM. Open Source Epidemiologic Statistics for Public Health (OpenEpi), Version 2013. [citado 25 Ago 2021]. Disponible en: https:// www.openepi.com/Menu/OE_Menu.htm

17. Textor J, van der Zander B, Gilthorpe MS, Liskiewicz M, Ellison GT. Robust causal inference using directed acyclic graphs: the R package 'dagitty'. Int J Epidemiol. 2016;45:1887-1894.

18. Müller L, Andrée M, Moskorz W, Drexler I, Walotka L, Grothmann R, et al. Age-dependent immune response to the Biontech/Pfizer BNT162b2 COVID-19 vaccination. Clin Infect Dis. 2021:ciab381.

19. Abu Jabal K, Ben-Amram H, Beiruti K, Batheesh Y, Sussan C, Zarka S, et al. Impact of age, ethnicity, sex and prior infection status on immunogenicity following a single dose of the BNT162b2 mRNA COVID-19 vaccine: real-world evidence from healthcare workers, Israel, December 2020 to January 2021. Euro Surveill. 2021;26:2100096.

20. Soiza RL, Scicluna C, Thomson EC. Efficacy and safety of COVID-19 vaccines in older people. Age Ageing. 2021;50(2):279-283.

21. Bossé $Y$, Xiao F, Kheradmand F, Amos $\mathrm{Cl}$. Tobacco Smoking Increases the Lung Gene Expression of ACE2, the Receptor of SARS-CoV-2. Am J Respir Crit Care Med. 2020;201(12):1557-1559.

22. Brake SJ, Barnsley K, Lu W, McAlinden KD, Eapen MS, Sohal SS. Smoking Upregulates Angiotensin-Converting Enzyme-2 Receptor: A Potential Adhesion Site for Novel Coronavirus SARS-CoV-2 (Covid-19). J Clin Med. 2020;9(3):841.

23. Watanabe M, Balena A, Tuccinardi D, TozziR, Risi R, Masi D, et al. Central obesity, smoking habit, and hypertension are associated with lower antibody titres in response to COVID-19 mRNA vaccine. Diabetes Metab Res Rev. 2021:e3465.

24. Grzelak L, Velay A, Madec Y, Gallais F, Staropoli I, Schmidt-Mutter C, et al. Sex differences in the evolution of neutralizing antibodies to SARS-CoV-2. J Infect Dis. 2021:jiab127. 
25. Gerhards C, Thiaucourt M, Kittel M, Becker C, Ast V, Hetjens M, et al. Longitudinal assessment of anti-SARS-CoV-2 antibody dynamics and clinical features following convalescence from a COVID-19 infection. Int J Infect Dis. 2021;107:221227.

26. Pellini R, Venuti A, Pimpinelli F, Abril E, Blandino G, Campo F, et al. Initial observations on age, gender, BMI and hypertension in antibody response to SARS-CoV-2 BNT162b2 vaccine. E Clinical Medicine 2021:100928.

27. Soffer S, Glicksberg BS, Zimlichman E, Efros O, Levin MA, Freeman R, et al. The association between obesity and peak antibody titer response in COVID-19 infection. Obesity (Silver Spring). 2021:10.1002/oby.23208.

28. Manisty C, Otter AD, Treibel TA, McKnight Á, Altmann DM, Brooks T, et al. Antibody response to first BNT162b2 dose in previously SARS-CoV-2-infected individuals. Lancet. 2021;397:1057-1058.

29. Tré-Hardy M, Cupaiolo R, Papleux E, Wilmet $A$, Horeanga A, Antoine-Moussiaux $\mathrm{T}$, et al. Reactogenicity, safety and antibody response, after one and two doses of mRNA-1273 in seronegative and seropositive healthcare workers. J Infect. 2021:S0163-4453(21)00158-4.

30. Krammer F, Srivastava K, Alshammary H, Amoako AA, Awawda MH, Beach $\mathrm{KF}$, et al. Antibody responses in seropositive persons after a single dose of SARSCoV-2 mRNA vaccine. N Engl J Med. 2021;384(14):1372-1374.

31. Favresse J, Bayart JL, Mullier F, Dogné JM, Closset M, Douxfils J. Early antibody response in healthcare professionals after two doses of SARS-CoV-2 mRNA vaccine (BNT162b2). Clin Microbiol Infect. 2021:S1198-743X(21)00224-X.

32. Schaffner A, Risch L, Aeschbacher S, Risch C, Weber MC, Thiel SL, et al. Characterization of a Pan-Immunoglobulin Assay Quantifying Antibodies Directed against the Receptor Binding Domain of the SARS-CoV-2 S1-Subunit of the Spike Protein: A Population-Based Study. J Clin Med. 2020;9(12):3989.

33. Harris RJ, Whitaker HJ, Andrews NJ, Aiano F, Amin-Chowdhury Z, Flood J, et al. Serological surveillance of SARS-CoV-2: Six-month trends and antibody response in a cohort of public health workers. J Infect. 2021;82(5):162-169.

34. Callegaro A, Borleri D, Farina C, Napolitano G, Valenti D, Rizzi M, et al. Antibody response to SARS-CoV-2 vaccination is extremely vivacious in subjects with previous SARS-CoV-2 infection. J Med Virol. 2021;93(7):4612-4615.

35. Ruiz-Galiana J, Cantón R, De Lucas-Ramos P, García-Botella A, García-Lledó A, Gómez-Pavón J, et al. Vacunación anti-COVID-19: La realidad tras los ensayos clínicos. Rev Esp Quimioter. 2021:ruiz28apr2021. 


\section{Anexo-1}

\section{CUESTIONARIO POST-VACUNACION SARS-CoV-2}

No aleatorización:

\section{DATOS PERSONALES:}

SIP

Edad: Sexo: Peso $(\mathrm{kg})$ : altura $(\mathrm{m})$ :

Ocupación: Centro Sanitario:

Tabaco: Fumador Exfumador No-fumador

Bebidas alcohólicas: No consume Consumo esporádico Consumo habitual ¿Realiza ejercicio físico habitualmente? Sí No

\section{ENFERMEDAD POR COVID-19:}

-¿Ha tenido exposición con pacientes SARS-CoV-2?:

No Si (detallar): Trabajo, familia, social...

-Se ha realizado anteriormente una serología de anticuerpos anti-SARS-CoV-2: No $\mathrm{Si}$

-¿Ha sufrido la enfermedad COVID-19? No Sí

Fecha de inicio: Síntomas:

Hospitalización: No Si

\section{SITUACIÓN DE SALUD:}

¿¿Cómo es su salud habitual?: mala regular buena muy buena ¿Sufre alguna enfermedad? No Si (detallar):

¿Toma habitualmente algún medicamento? No Si (detallar):

¿Toma vitaminas habitualmente? No Si (detallar):

\section{VACUNACIÓN:}

Fecha de la primera dosis vacuna: Fecha de la segunda dosis:

¿Ha sufrido síntomas después de la vacunación? N o Sí (rellenar tabla)

¿Ha requerido atención sanitaria por la vacunación? No Sí 
ENROJECIMIENTO

HINCHAZÓN

DOLOR BRAZO

MIALGIAS

ARTRALGIAS

FIEBRE

CEFALEA

FATIGA

MAREOS

VÓMITOS

DIARREA

ERUPCIÓN

DIFICULTAD RESPIRATORIA

-Otra sintomatología:

\section{OBSERVACIONES:}

-¿Quiere añadir algún aspecto que piense de interés? 